\title{
IMPACT OF TECHNOLOGY ON A TOP 20 GLOBAL 100 LEGAL FIRM
}

\author{
Theophilus D.Owusu, Keiser University, towusu@keiseruniversity.edu \\ John J. Scarpino, Robert Morris University, scarpino@rmu.edu
}

\begin{abstract}
An attorney at law is defined as a practitioner in a court of law who is legally qualified to prosecute and defend actions of clients in a court (Flood and Sosa, 2008). Attorneys are also referred to as a lawyers or counselors. Lawyers are trained individuals who are licensed by the state in which they practice law in legal matters and provide legal advice (Hunter, 2008). Few law schools offer training on technology software aids. As a result attorneys enter the field of law with knowledge regarding laws and the processes of law; however they often display a lack of basic technological skills. The inability to employ technologically advanced systems such as Personal Digital Assistants (PDA devices), FileSite ${ }^{\circledR}$ (an electronic document management database), and WordTricks ${ }^{\circledR}(a$ toolbar in Microsoft Word $\mathbb{\circledR}$ designed to make it easier to create documents) results in the loss of time and money for a firm.
\end{abstract}

Keywords: Technology, Legal, Document Management, Mobile, Smartphone, PDA, FileSite, WordTricks, Time Management, Productivity, Office Location, Legal IT.

\section{INTRODUCTION}

Both researchers worked for different top global legal firms located within the United States; one as a Senior IT Specialist, and the other as an IT Director. According to the researchers' experiences, similar technological trends impacted these two firms and the industry of law. The research focused on a top 20 global firm located in Florida. Technology is made available in the law firm to promote time-efficient tasks and to provide resources that allows the accurate billing and storing of documents. This study examined the impact of three major technologies that are used by attorneys in a law firm. Quantitative procedures facilitated the identification of barriers to Personal Digital Assistants (PDA devices), FileSite ${ }^{\circledR}$ (an electronic database), and WordTricks ${ }^{\circledR}$ (a toolbar in Microsoft Word ${ }^{\circledR}$ designed to make it easier to create documents). Attorneys enter the field of law with knowledge regarding laws and the processes of law; however they often lack basic technological skills. The inability to employ technologically advanced systems such as PDA devices, FileSite, and WordTricks results in the lost of time and money for a firm.

The purpose of this research was to (1) obtain information about the utilization of PDA devices, FileSite and WordTricks, (2) analyze the firm's ability to determine their return on investments with those technologies, (3) are the attorneys using their time more efficiently by using these technologies, (4) has professional development in the usage of the technologies improving the attorney's productivity and, (5) have age, gender, experience, and office location play a pivotal role in the confidence and use of the technologies. This research addressed the reasons why the use of those technologies are or not limited. It examined whether technology is or not utilized and the reasons for this usage or lack thereof. Pearson's chi-square analysis was utilized to determine statistical significance between two categories. The research indicated that $11.4 \%$ of the attorneys that use their PDA devices actually record billable hours. $84.3 \%$ of the attorneys save Word documents into FileSite, $64.3 \%$ of the attorneys save PDF documents into FileSite and $48.6 \%$ of the attorneys save emails into FileSite. The data indicated in every WordTricks feature there are more attorneys that do not use the feature then there are attorneys that do use the feature. Furthermore, $34.3 \%$ of the attorneys don't use WordTricks. Training did improve attorneys' productivity in the use of WordTricks. Age, gender and experience played a pivotal role in the confidence and use of FileSite. However, PDA devices and WordTricks were not statistically significant.

\section{Background}

Connecting the firm, its attorneys and technology is vital to this research. There are software programs that are utilized on a daily basis within a law firm that are intended to make the attorney's work effortless. TimeEntry is a program used to record billable and non-billable time for clients. Content Management System (CMS) is the firm's billable time system for its clients. The CMS open time accounting module provides an extensive variety of features, which ensures an accurate and prompt account of billable, non-billable, or otherwise accountable time. Time 


\section{Issues in Information Systems \\ Volume 14, Issue 1, pp.133-142, 2013}

accounting allows employees to record time sheets via an easily understood and convenient entry method. Microsoft Office ${ }^{\circledR}$ is applied for producing needed files and documents for clients. In addition, FileSite, a Matter-Centric Document Management System (DMS) in Outlook, integrates with Microsoft Office, Adobe and graphics files such as TIFS and JPG. This program permits attorneys to easily manage files from most of their Microsoft Office applications.

The firm utilizes a toolbar called WordTricks, a resident in Microsoft Word, and integrates with Microsoft Outlook. WordTricks, as the name implies, is a program that assists users by automating some of the "tricks" that Microsoft Word requires in performing various actions. WordTricks is also a comprehensive tool for WordTricks users that expedites the production of professional legal documents. WordTricks is designed to place commonly used items and formatting such as forms, letters, memos, fax coversheet structures and watermarks within a click's reach. WordTricks is also used to create Bate Stamp labels, insertion of documents' tag lines, format paragraphs with tab leaders and common indentation commands and access many firm-wide standard forms like the firm's labels and the travel and expense forms as well as various pleading and legal forms. An important feature in WordTricks is Number-It. Number-It provides quick and precise conversion of typed paragraph or outline numbering that is automated and ties into the entire paragraph formatting and use of text with a touch.

There are also research tools that allow the retrieval of information that is conducive to the attorney's field of work (Lexus $\operatorname{Nexus}^{\circledR}$, Westlaw ${ }^{\circledR}$ and the firm's research centers' intranet site). Regardless of an individual attorneys' need a PDA device will enable him/ her to accomplish several tasks by keeping them in touch with the necessary information and their staff while away from the office. A PDA device enables access to a variety of data and communication services including Outlook email, calendar and contacts, CMS Time Entry, the internet and more. A feature known as QwikTime, an offline entry program designed for the Blackberry PDA streamlines an attorney's travel time that results in efficient billable hours for clients. In addition, the aforementioned PDA's track all information relevant to the cases of clients.

\section{RESEARCH METHODOLOGY}

The following four research questions guided this study.

1. How can the firm improve their return on investments by improving their utilization of PDA devices, FileSite and WordTricks?

2. How can attorneys use their time more efficiently by using PDA devices, FileSite and WordTricks?

3. Has professional development in the usage of PDA devices, FileSite and WordTricks improved attorneyproductivity?

4. Have age, gender, experience and office location played a pivotal role in the confidence and usage of PDA devices, FileSite and WordTricks?

The framework of this study was that of a quantitative survey in determining the relationship between attorney acceptance and use of technology in a law firm. In this study the method of data collection was a survey instrument. A sample group of 70 attorneys were selected from the law firm in the South Florida office.

This study used an explorative research design. Babbie (2004) states, "much of social research is conducted to explore a topic, that is, to start to familiarize a researcher with that topic" (p. 87). The process used in this study to collect data was the survey method. The purpose of the survey was to make it possible to generalize results by a sample of attorneys in the organization to all the attorneys in its population (Creswell, 2003). The survey was conducted as an explorative approach as aforementioned and administered to the attorneys from July 14, 2009, until September 29, 2009. The size of the firm that was studied comprised of over 1,000 attorneys in different locations world wide. One office, with two different locations, was chosen to participate in this research. The attorneys selected for this research were a convenient population for the study since they were all from a nearby location (Babbie, 1990). The survey was administered to 70 attorneys to determine the usage of PDA devices, FileSite and WordTricks. The survey given to the sample of 70 consisted of 30 multiple choice questions. 


\section{Issues in Information Systems}

Volume 14, Issue 1, pp.133-142, 2013

\section{Participants}

The South County Florida location consisted of 30 attorneys, while the North County Florida location consisted of 40 attorneys. The locations are 26 miles apart from each other. Participants graduated from law school and were practicing law at the time of the study. The participants included males and females from various age groups. They were fluent in speaking, writing and reading the English language. The participants specialized in the following legal areas: real estate, corporate, tax, environmental, litigation, public finance and government.

The participants of this study were recruited by introducing this study and its benefits to the law firm via email and face-to-face meetings. Questions were asked by attorneys regarding the length of time for the research and what was needed on their part.

\section{Data Collection}

An email was sent to every attorney at the South Florida law firm. The email contained a cover letter with an explanation of the nature and purposes of the study, a participant's consent form, and a link to access the survey from their computer.

Three follow-up emails were sent to encourage responses from attorneys. The first follow-up was to inform them that the survey took, on average, five minutes to complete. It also advised them that if they were to contact the researcher if they had any issues accessing the link. The second follow-up was to remind them of the purpose of the research study and that they should complete the survey. The third follow-up was to notify the attorneys that the survey would close soon, and they should access the link to the survey before the deadline of September 29, 2009. The questions on the survey were created by the researcher and sent out via email to participants in the South Florida office. The survey was created through Survey Monkey. Survey Monkey is a user-friendly website which allows the user to create and distribute a survey (Nesbary, 2000). Survey Monkey provides software that compiles responses from the participants.

\section{Survey Questions}

Demographic portion of the survey:

1. Please mark the appropriate range for your age.

(A) 24 Years or Less $=1$, (B) 25-30 Years $=2$, (C) 31-35 Years $=3$, (D) 36-40 Years $=4$,

(E) 41-45 Years = 5, (F) 46-50 Years =6, (G) 51-55 Years = 7, (H) 56-60 Years = 8, (I) 61-65 Years = 9,

(J) $66-70$ Years $=10,(\mathrm{~K}) 71$ Years or More $=11$

2. What is your gender?

(A) Male $=1$, (B) Female $=2$

3. Where is your primary office location?

(A) South County $=1$, (B) North County $=2$

4. How long have you been employed with the firm?

(A) 1-5 Years = 1, (B) 6-10 Years $=2$, (C) 11-15 Years =3, (D) 16-20 Years $=4$, (E) 21-25 Years = 5,

(F) 26-30 Years $=60,(\mathrm{G}) 31$ Years or More $=7$

5. How many years have you been practicing law?

(A) 1-5 Years $=1$, (B) 6-10 Years $=2$, (C) 11-15 Years $=3$, (D) 16-20 Years $=4$, (E) 21-25 Years $=5$

(F) 26-30 Years $=6,(\mathrm{G}) 31$ Years or More $=7$

6. What type of law do you practice?

(A) Real Estate = 1, (B) Corporate = 2, (C) Tax =3, (D) Environment $=4$, (E) Litigation $=5$,

(F) Public Finance $=6,(\mathrm{G})$ Governmental Affairs $=7$

7. How long have you been practicing law in your current practice group?

(A) 1-5 Years $=1$, (B) 6-10 Years $=2$, (C) 11-15 Years $=3$, (D) 16-20 Years $=4$, (E) 21-25 Years $=5$

(F) 26-30 Years $=6,(\mathrm{G}) 31$ Years or More $=7$ 


\section{Issues in Information Systems}

Volume 14, Issue 1, pp.133-142, 2013

PDA Devices portion of the survey:

1. I use technology that relates to my practice area.

(A) Strongly Agree $=1$, (B) Agree $=2$, (C) Neither Agree nor Disagree $=3$, (D) Disagree $=4$,

(E) Strongly Disagree $=5$

2. What program do you use to bill time?

(A) Basic Time Entry = 1, (B) CMS Enhanced Time Entry $=2$

3. Do you own a PDA device (BlackBerry, iPhone, Treo, etc.)?

(A) $\mathrm{Yes}=1,(\mathrm{~B}) \mathrm{No}=2$

4. How confident are you with the use of your PDA device?

(A) Extremely confident $=1$, (B) Fairly confident $=2$, (C) Somewhat confident $=3$,

(D) Barely confident $=4$, (E) Not confident $=5$, (F) I don't own a PDA device $=6$

5. How often do you use your PDA device?

(A) Daily $=1$, (B) 3 times per week $=2$, (C) Once per week $=3$, (D) Never $=4$,

(E) I don't own a PDA device $=5$

6. Does your PDA device help you service your clients readily when you're out of the office?

(A) $\mathrm{Yes}=1$, (B) $\mathrm{No}=2$, (C) I don't own a PDA device $=3$

7. How often do you use CMS Time Entry to bill time with your PDA device (BlackBerry)?

(A) Daily $=1$, (B) Three times per week $=2$, (C) Once per week $=3$, (D) Never $=4$,

(E) My PDA device (iPhone, Treo, etc.) does not support CMS Time Entry $=5$,

(F) I don't have it installed on my PDA device (BlackBerry) $=6$, (G) I don't own a PDA device $=7$

FileSite portion of the survey:

1. When saving Word documents where do you store them?

(A) User drive on the server (E: drive) $=1$, (B) On your Desktop = 2, (C) My Documents = 3,

(D) File Site $=4$, (E) My Secretary does it for me $=5$

2. When saving PDF documents where do you store them?

(A) User drive on the server (E: drive) $=1$, (B) On your Desktop =2, (C) My Documents = 3,

(D) File Site $=4$, (E) Personal Folder in Outlook $=5$, (F) My Secretary does it for me $=6$

3. Where do you save emails from clients?

(A) Personal Folder in Outlook =1, (B) Archive Folder in Outlook =2, (C) File Site $=3$, (D) Inbox $=4$

4. How often do you use File Site?

(A) Daily $=1$, (B) Three times per week =2, (C) Once per week $=3$, (D) Never $=4$

5. How confident are you with the use of File Site?

(A) Extremely confident $=1$, (B) Fairly confident $=2$, (C) Somewhat confident $=3$,

(D) Barely confident $=4$, (E) Not confident $=5$

6. What obstacles prevent you from using File Site to its fullest capability?

(A) Lack of time for training $=1$, (B) Too complicated $=2$, (C) Secretary does it for me $=3$,

(D) I don't use it $=4$, (E) I believe I use it to the fullest $=5$

WordTricks portion of the survey:

1. Which of the following WordTricks features do you use? Select all that apply.

(A) Contax Rolodex $=1$, (B) Add a Contact to Outlook $=2$, (C) Letterhead Generator $=3$,

(D) Fax Cover Page = 4, (E) Memo Generator $=5$, (F) Label Generator $=6,(\mathrm{G})$ Envelope Generator $=7$,

(H) Set Default Font to Author's = 8, (I) Signature Block = 9, (J) Draft Stamp $=10$,

(K) Watermark, Generator $=11$, (L) Bates Stamp Labels $=12$, (M) Date Insert $=13$,

(N) Bar / Certificate Numbers $=14,(\mathrm{O})$ Special Symbols $=15,(\mathrm{P})$ Print to Tray $=16$,

(Q) Page Numbering =17, (R) Firm Autotext $=18$, (S) Number-It! $=19$, (T) Formats $=20$,

(U) Qlick Forms $=21,(\mathrm{~V})$ WordTricks Menu and Help System $=22$

2. Would you say that WordTricks for Microsoft Word is helpful in saving time?

(A) Extremely helpful $=1$, (B) Fairly helpful $=2$, (C) Somewhat helpful $=3$, (D) Barely helpful $=4$

(E) Not at all helpful $=5$, (F) I don't use it $=6$

3. How confident are you with the use of WordTricks?

(A) Extremely confident $=1$, (B) Fairly confident $=2$, (C) Somewhat confident $=3$, 


\title{
Issues in Information Systems \\ Volume 14, Issue 1, pp.133-142, 2013
}

(D) Barely confident $=4$, (E) Not confident $=5$

4. How often do you use WordTricks?

(A) Daily $=1$, (B) Three times per week $=2$, (C) Once per week $=3$, (D) Never $=4$

Training portion of the survey:

1. What type of training do you utilize to learn new technology? Select all that apply.

(A) West LegalEdcenter $=1$, (B) Professional Development Center $=2$,

(C) Tech Institute $=3$, (D) In House Trainer $=4$, (E) Self Training $=5$, (F) Secretary teaches me $=6$

2. After the initial training of PDA devices, File Site and WordTricks, how often have you requested further training?

(A) Often $=1$, (B) Occasionally $=2$, (C) Rarely $=3$, (D) Never $=4$

3. How effective overall do you think the company's training is for PDA devices?

(A) Extremely Effective =1, (B) Fairly Effective = 2, (C) Somewhat Effective = 3,

(D) Barely Effective $=4$, (E) Not Effective $=5$

4. How effective overall do you think the company's training is for File Site?

(A) Extremely Effective = 1, (B) Fairly Effective = 2, (C) Somewhat Effective = 3,

(D) Barely Effective $=4$, (E) Not Effective $=5$

5. How effective overall do you think the company's training is for WordTricks?

(A) Extremely Effective = 1, (B) Fairly Effective = 2, (C) Somewhat Effective = 3,

(D) Barely Effective $=4$, (E) Not Effective $=5$

6. What is your biggest obstacle when it comes to training or learning new technology?

(A) Lack of time $=1$, (B) I rely on others for support $=2$, (C) Resources are not readily available $=3$

(D) Don't see the need $=4$, (E) I need hands on Training $=5$, (E) Hard to learn complicated programs $=6$

\begin{abstract}
ANALYSIS
Results were analyzed through Statistical Package for the Social Scientist (SPSS), a computer program that statistically correlates data. Univariate analysis aided in the process of describing the sample by examining and summarizing the distribution of each individual variable to get the descriptive statistics of frequencies with percentages (Babbie, 2004). The researchers collapsed the demographic information into groups to conduct a chisquare analysis to compare the groups. Chi-square analysis was used to determine statistical significance between two categories to answer research questions 3 and 4. Furthermore, descriptive statistics assisted in comparing frequencies with percentages between pairs of variables to answer research questions 3 and 4 . The surveys from the website were encoded and entered into Microsoft Excel, then exported into SPSS for data analysis and finally graphed by Microsoft Excel.
\end{abstract}

\section{RESULTS}

The survey was distributed to 70 attorneys from two different locations. The South County Florida location consists of 30 attorneys, while the North County Florida location consists of 40 attorneys. 100 percent participation in the survey was achieved. Below are the results based on the breakdown of each research question.

\section{Research Question One Findings}

The first research question explored the use of PDA devices, FileSite and WordTricks to determine if the firm can improve their return on investments with the technology. The data was analyzed through descriptive statistics regarding frequencies with percentages. The results of the data for the use of PDA devices indicated that $97.1 \%$ of the attorneys own PDA devices and $2.9 \%$ of the attorneys don't possess PDA devices. Two attorneys declined the use of the PDA device. Although $97.1 \%$ of the attorneys own PDA devices, $60 \%$ of the attorneys indicated that they do not use it to bill clients for their time. The PDA devices of $15.7 \%$ of these attorneys do not support the program and $10 \%$ of the attorneys do not have the billing program installed on their PDA devices. Only $11.4 \%$ of the attorneys that use their PDA devices actually record billable hours. If the firm implemented a policy for all attorneys to utilize their PDA devices for billable hours, they could improve their return on investment. Based on the data analysis the firm should communicate the loss of revenue to all attorneys in order to improve ROI by $88.6 \%$. As a 


\section{Issues in Information Systems \\ Volume 14, Issue 1, pp.133-142, 2013}

result, attorneys who fail to record billable hours would lose revenue. Therefore, the firm should integrate the IT department with the $15.7 \%$ of attorneys whose PDA devices do not support the software, to insure compatibility with the firm's proprietary (CMS) time management program. All attorneys (including the $2.9 \%$ of attorneys who do not posses PDA devices) and the firm would benefit by using PDA devices to record billable hours.

The data for the use of FileSite indicates that $88.6 \%$ of the attorneys use FileSite and $11.4 \%$ of the attorneys do not. $84.3 \%$ of the $88.6 \%$ attorneys save Word documents in FileSite, while $15.7 \%$ of these attorneys save Word documents in different locations. When saving PDF documents, $64.3 \%$ of the $88.6 \%$ of attorneys use FileSite, while $35.7 \%$ of these attorneys store PDF's in different locations. $48.6 \%$ of the $88.6 \%$ of attorneys save emails in FileSite, while $51.4 \%$ of these attorneys save them in different locations. Since the firm allocates capital in FileSite, the improper storage of documents may hinder the firm's return on investment and slows data sharing and collaboration amongst attorneys, paralegals and their secretaries. Therefore, the firm should train all employees on the proper storage of documents in FileSite. The firm could save time and improve their return on investment if all attorneys saved their documents and emails in one central location such as in FileSite.

The data for the use of WordTricks indicated that $61.4 \%$ of the attorneys use WordTricks and $38.6 \%$ of the attorneys never use WordTricks. In regards to the features in WordTricks $14.3 \%$ of the attorneys use contax rolodex and $85.7 \%$ of the attorneys do not use it. In addition, $44.3 \%$ of the attorneys uses add a contact to outlook feature and $55.7 \%$ of the attorneys do not use it. Also, $31.4 \%$ of the attorneys use letterhead generator feature and $68.6 \%$ of the attorneys do not use it. In addition, $25.7 \%$ of the attorneys use the fax cover page feature and $74.3 \%$ of the attorneys do not use it. Furthermore, $40 \%$ of the attorneys use the memo generator feature and $60 \%$ of the attorneys do not use it. Yet, $2.9 \%$ of the attorneys use the label generator feature and $97.1 \%$ of the attorneys do not use it. In addition, $5.7 \%$ of the attorneys use the envelope generator feature and $94.3 \%$ of the attorneys do not use it. Also, $0 \%$ of the attorneys use the set default font to author's feature and $100 \%$ of the attorneys do not use it. Likewise, $37.1 \%$ of the attorneys use the signature block feature and $62.9 \%$ of the attorneys do not use it. Yet, $18.6 \%$ of the attorneys use the draft stamp feature and $81.4 \%$ of the attorneys do not use it. Furthermore, $11.4 \%$ of the attorneys use the watermark generator feature and $88.6 \%$ of the attorneys do not use it. In addition, $1.4 \%$ of the attorneys use the bate stamp label feature and $98.6 \%$ of the attorneys do not use it. Also, $21.4 \%$ of the attorneys use the date insert feature and $78.6 \%$ of the attorneys do not use it. In addition, $2.9 \%$ of the attorneys use the bar/certificate numbers feature and $97.1 \%$ of the attorneys do not use it. Furthermore, $11.4 \%$ of the attorneys use the special symbols feature and $88.6 \%$ of the attorneys do not use it. Yet, $17.1 \%$ of the attorneys use the print to tray feature and $82.9 \%$ of the attorneys do not use it. Also, $41.4 \%$ of the attorneys use the page numbering feature and $58.6 \%$ of the attorneys do not use it, $1.4 \%$ of the attorneys use the firm auto-text feature and $98.6 \%$ of the attorneys do not use it. Likewise, $21.4 \%$ of the attorneys use the number-it feature and $78.6 \%$ of the attorneys do not use it. Furthermore, $7.1 \%$ of the attorneys use the formats feature and $92.9 \%$ of the attorneys do not use it. Also, $1.4 \%$ of the attorneys use the feature qlick forms and $98.6 \%$ of the attorneys do not use it. Finally $5.7 \%$ of the attorneys use the WordTricks menu and help system feature while $94.3 \%$ of the attorneys do not use it. The data indicated reveals that for every WordTricks tool available there are more attorneys that do not use the feature then there are attorneys that do use the feature. The firm also allocates capital to update and maintain WordTricks. Since the majority of attorneys do not utilize WordTricks the lack of usage as indicated by the data diminishes ROI for the firm. This data should be shared and communicated to all employees. As a result more attorneys may begin utilizing several of the WordTricks features which can expedite their tasks and also improve the firms ROI.

\section{Research Question Two Findings}

The second research question explored the use of PDA devices, FileSite and WordTricks to determine if attorneys can use their time more efficiently by using the available technologies. The data was analyzed through descriptive statistics regarding frequencies with percentages. The results of the data indicated that $97.1 \%$ of the attorneys alleged that the use of PDA device helps them service their clients. Attorneys answer client emails, collaborate Word data and PDF documents while away from their desks or out of the office; thus the survey confirms that utilization of PDA devices helps attorneys efficiently manage their time by communicating with clients and law firm employees while away from their desks. Furthermore, although only $11.4 \%$ of the $97.1 \%$ sample recorded billable hours via PDA devices, this results in enhanced time management because the electronic recording of billable hours through PDA devices requires less time than by the means of TimeEntry software through their computers.

The data for the use of FileSite indicated that $88.6 \%$ of the attorneys use FileSite and $11.4 \%$ of the attorneys do not use FileSite. When saving Word documents $84.3 \%$ of the $88.6 \%$ attorneys save it in FileSite and $15.7 \%$ of the 


\section{Issues in Information Systems \\ Volume 14, Issue 1, pp.133-142, 2013}

$88.6 \%$ attorneys save it in different locations. When saving PDF documents $64.3 \%$ of the $88.6 \%$ attorneys save it in FileSite and $35.7 \%$ of the $88.6 \%$ attorneys store it in different locations. When saving emails from clients $48.6 \%$ of the $88.6 \%$ attorneys save them in FileSite and $51.4 \%$ of the $88.6 \%$ attorneys save them in different locations. The research demonstrates that $84.3 \%$ of the $88.6 \%$ of attorneys that save word documents in FileSite along with $64.3 \%$ of the $88.6 \%$ of attorneys who save PDF documents and $48.6 \%$ of the $88.6 \%$ of attorneys who save email correctly in FileSite maximize their time efficiently. By properly storing all documents in FileSite attorneys are able to access the firm's client information centrally and expedite their tasks instead of scrambling around to search for documents and asking other attorneys and administrative personnel for it. By improperly storing documents attorneys also expend the time of other firm employees and directly create lost wages for the firm. Furthermore, if an attorney or a sub-group of attorneys store their data in a few locations instead of a matter-centric database such as FileSite accessible to all; the consequences may be harmful if their computers are damaged or plagued with a virus or malfunctions resulting in the loss of client information. Therefore the sample of $84.3 \%$ of attorneys that save Word documents properly, $64.3 \%$ of the attorneys which save PDF documents correctly and $48.6 \%$ of the attorneys who save emails appropriately demonstrates that attorneys can utilize time efficiency by storing documents in FileSite.

The data that inquired if the attorneys feel that WordTricks for Microsoft Word is helpful in saving time indicated only $11.4 \%$ of the attorneys responded extremely helpful, $24.3 \%$ of the attorneys responded fairly helpful, $21.4 \%$ of the attorneys responded somewhat helpful, $7.1 \%$ of the attorneys responded barely helpful, $1.4 \%$ of the attorney responded not at all helpful and 34.3\% of the attorneys responded I don't use it. Based on the results most attorneys do not use WordTricks features. However if all attorneys utilize WordTricks' features such as letterhead generator or fax cover page which has the firm's information at the top, it would expedite the process of creating letters or fax cover sheets instead of manually typing the information and would result in saving time. Other examples are envelope, label and stamp generators which automatically print the firm's, attorneys, and client information on the postage with a single click so that attorneys or their secretaries do not have to manually write the information wasting their time along with the firm's wages. Furthermore a feature such as page numbering maximizes time by pre-filling documents with page numbers before attorneys or secretaries begin typing their memos or letters. The small sample of attorneys who utilize WordTricks features demonstrate through the data that WordTricks assists them in time management if it is utilized to its full potential.

\section{Research Question Three Findings}

The third research question explored if professional development in the usage of PDA devices, FileSite and WordTricks improved attorney productivity. The results from the survey indicated that there was not a statistically significant relationship between the use of the PDA device and the overall training for PDA devices $\left(\chi^{2}=5.410, d f=\right.$ $4, \mathrm{p}=>$.248). Furthermore, there was not a statistically significant relationship between the use of the PDA device for billing time and the age of the user $\left(\chi^{2}=3.807, d f=2, \mathrm{p}=>.149\right)$. Many attorneys indicated that the firms' overall training for PDA devices was extremely helpful but did not use their PDA device to bill time. Training did not improve attorneys' productivity with the use of PDA devices.

The results from the survey indicated that there was a statistically significant relationship between the use of FileSite and the overall training for FileSite $\left(\chi^{2}=11.452, d f=2, \mathrm{p}=<.003\right)$. Furthermore, there was a statistically significant relationship between the locations where word documents are stored and the overall training for FileSite $\left(\chi^{2}=\right.$ 17.203, $d f=8, \mathrm{p}=<.028)$. In addition, there was a statistically significant relationship between the locations where PDF documents are stored and the overall training for FileSite $\left(\chi^{2}=20.503, d f=10, \mathrm{p}=<.025\right)$. On the other hand there was not a statistically significant relationship between the locations where emails are stored and the overall training for FileSite $\left(\chi^{2}=10.773, d f=6, \mathrm{p}=>.096\right)$. Training did improve attorneys' productivity in the use of FileSite with the exception of storing emails in their proper location. The results from the survey indicated that there was a statistically significant relationship between the use of WordTricks and the overall training for WordTricks $\left(\chi^{2}\right.$ $=8.885, d f=2, \mathrm{p}=<.012$ ). In addition, there was a statistically significant relationship between the use of WordTricks and the overall training for WordTricks $\left(\chi^{2}=20.728, d f=4, \mathrm{p}=<.000\right)$. Training did improve attorneys' productivity in the use of WordTricks.

\section{Research Question Four Findings}

The fourth research question explored if age, gender, experience and office location played a pivotal role in the confidence and use of PDA devices, FileSite and WordTricks. The results from the survey indicated that there was not a statistically significant relationship between the use of the PDA device and the age of the user $\left(\chi^{2}=.959, d f=\right.$ $2, \mathrm{p}=>$.619). Also, there was not a statistically significant relationship between the use of the PDA device for 


\section{Issues in Information Systems \\ Volume 14, Issue 1, pp.133-142, 2013}

billing time and the age of the user $\left(\chi^{2}=2.009, d f=1, \mathrm{p}=>.156\right)$. Furthermore, there was not a statistically significant relationship between the confidence with the use of the PDA device and the age of the user $\left(\chi^{2}=.012, d f\right.$ $=2, p=>$.994). Age did not play a pivotal role in the confidence and use of PDA devices. The results from the survey indicated that there was not a statistically significant relationship between the use of the PDA device and the gender of the user $\left(\chi^{2}=2.379, d f=2, p=>.304\right)$. Furthermore, there was not a statistically significant relationship between the use of the PDA device for billing time and the gender of the user $\left(\chi^{2}=.088, d f=1, \mathrm{p}=>.766\right)$. Also, there was not a statistically significant relationship between the confidence with the use of the PDA device and the gender of the user $\left(\chi^{2}=.304, d f=2, \mathrm{p}=>.859\right)$. Gender did not play a pivotal role in the confidence and use of PDA devices.

The results from the survey indicated that there was not a statistically significant relationship between the use of the PDA device and the office location of the user $\left(\chi^{2}=.797, d f=2, \mathrm{p}=>.671\right)$. Furthermore, there was not a statistically significant relationship between the use of the PDA device for billing time and the office location of the user $\left(\chi^{2}=.188, d f=1, \mathrm{p}=>.664\right)$. Also, there was not a statistically significant relationship between the confidence with the use of the PDA device and the office location of the user $\left(\chi^{2}=.809, d f=2, p=>.667\right)$. Office location did not play a pivotal role in the confidence and use of PDA devices. The results from the survey indicated that there was not a statistically significant relationship between the use of the PDA device and the experience of the user $\left(\chi^{2}=\right.$ $1.148, d f=2, \mathrm{p}=>.563)$. Furthermore, there was not a statistically significant relationship between the use of the PDA device for billing time and the experience of the user $\left(\chi^{2}=.855, d f=1, \mathrm{p}=>.355\right)$. Also, there was not a statistically significant relationship between the confidence with the use of the PDA device and the experience of the user $\left(\chi^{2}=.047, d f=2, p=>.977\right)$. Experience did not play a pivotal role in the confidence and use of PDA devices.

The results from the survey indicated that there was a statistically significant relationship between FileSite and the age of the user $\left(\chi^{2}=9.387, d f=1, \mathrm{p}=<.002\right)$. However, there was not a statistically significant relationship between the locations where word documents are stored and the age of the user $\left(\chi^{2}=8.580, d f=4, p=>.072\right)$. Furthermore, there was not a statistically significant relationship between the locations where PDF documents are stored and the age of the user $\left(\chi^{2}=4.245, d f=5, \mathrm{p}=>.515\right)$. In addition, there was not a statistically significant relationship between the locations where emails are stored and the age of the user $\left(\chi^{2}=3.348, d f=3, \mathrm{p}=>.341\right)$. Never the less there was a statistically significant relationship between the confidence with the use of FileSite and the age of the user $\left(\chi^{2}=11.249, d f=1, \mathrm{p}=<.001\right)$. Age did play a pivotal role in the confidence and use of FileSite. However, in regards to storing word documents, PDF documents and emails in FileSite age did not play a pivotal role.

The results from the survey indicated that there was a statistically significant relationship between the use of FileSite and the gender of the user $\left(\chi^{2}=3.948, d f=1, \mathrm{p}=<.047\right)$. However, there was not a statistically significant relationship between the locations where word documents are stored and the gender of the user $\left(\chi^{2}=3.836, d f=4, \mathrm{p}\right.$ $=>$.429). Also, there was not a statistically significant relationship between the locations where PDF documents are stored and the gender of the user $\left(\chi^{2}=9.533, d f=5, \mathrm{p}=>.090\right)$. In addition, there was not a statistically significant relationship between the locations where emails are stored and the gender of the user $\left(\chi^{2}=2.933, d f=3, p=>.402\right)$. Furthermore, there was not a statistically significant relationship between the confidence with the use of FileSite and the gender of the user $\left(\chi^{2}=1.022, d f=1, \mathrm{p}=>.312\right)$. Gender did play a pivotal role in the use of FileSite. However, while factoring in confidence for storing word documents, PDF documents and emails in FileSite gender did not play a pivotal role.

The results from the survey indicated that there was not a statistically significant relationship between the use of FileSite and the office location of the user $\left(\chi^{2}=.008, d f=1, p=>.927\right)$. Furthermore, there was not a statistically significant relationship between the locations where word documents are stored and the office location of the user $\left(\chi^{2}=2.853, d f=4, \mathrm{p}=>.583\right)$. Also, there was not a statistically significant relationship between the locations where PDF documents are stored and the office location of the user $\left(\chi^{2}=4.096, d f=5, \mathrm{p}=>.536\right)$. In addition, there was not a statistically significant relationship between the locations where emails are stored and the office location of the user $\left(\chi^{2}=6.380, d f=3, p=>.095\right)$. Moreover, there was not a statistically significant relationship between the confidence with the use of FileSite and the office location of the user $\left(\chi^{2}=1.353, d f=1, \mathrm{p}=>.245\right)$. Office location did not play a pivotal role in the confidence and use of FileSite.

The results from the survey indicated that there was a statistically significant relationship between the use of FileSite and the experience of the user $\left(\chi^{2}=11.522, d f=1, \mathrm{p}=<.001\right)$. In addition, there was a statistically significant relationship between the locations where word documents are stored and the experience of the user $\left(\chi^{2}=10.470, d f=\right.$ $4, \mathrm{p}=<.033)$. However, there was not a statistically significant relationship between the locations where PDF 


\section{Issues in Information Systems \\ Volume 14, Issue 1, pp.133-142, 2013}

documents are stored and the experience of the user $\left(\chi^{2}=7.523, d f=5, \mathrm{p}=>.185\right)$. Moreover, there was not a statistically significant relationship between the locations where emails are stored and the experience of the user $\left(\chi^{2}\right.$ $=2.122, d f=3, \mathrm{p}=>.548)$. Nevertheless, there was a statistically significant relationship between the confidence with the use of FileSite and the experience of the user $\left(\chi^{2}=11.374, d f=1, \mathrm{p}=<.001\right)$. Experience did play a pivotal role in the confidence and use of FileSite as well as storing word documents into FileSite. However, while researching the storing of PDF documents and emails in FileSite, experience did not play a pivotal role.

The results from the survey indicated that there was not a statistically significant relationship between the use of WordTricks and the age of the user $\left(\chi^{2}=2.745, d f=1, \mathrm{p}=>.098\right)$. In addition, there was not a statistically significant relationship between the confidence with the use of WordTricks and the age of the user $\left(\chi^{2}=1.354, d f=\right.$ $1, \mathrm{p}=>$.245). Age did not play a pivotal role in the confidence and use of WordTricks. The results from the survey indicated that there was not a statistically significant relationship between the use of WordTricks and the gender of the user $\left(\chi^{2}=2.612, d f=1, \mathrm{p}=>.106\right)$. Also, there was not a statistically significant relationship between the confidence with the use of WordTricks and the gender of the user $\left(\chi^{2}=.629, d f=1, \mathrm{p}=>.428\right)$. Gender did not play a pivotal role in the confidence and use of WordTricks. The results from the survey indicated that there was not a statistically significant relationship between the use of WordTricks and the office location of the user $\left(\chi^{2}=.005, d f=\right.$ $1, \mathrm{p}=>$.944). In addition, there was not a statistically significant relationship between the confidence with the use of WordTricks and the office location of the user $\left(\chi^{2}=.383, d f=1, \mathrm{p}=>.536\right)$. Office location did not play a pivotal role in the confidence and use of WordTricks.

The results from the survey indicated that there was not a statistically significant relationship between the use of WordTricks and the experience of the user $\left(\chi^{2}=2.312, \mathrm{df}=1, \mathrm{p}=>.128\right)$. Furthermore, there was not a statistically significant relationship between the confidence with the use of WordTricks and the experience of the user $\left(\chi^{2}=.790\right.$, $\mathrm{df}=1, \mathrm{p}=>$.374). Experience did not play a pivotal role in the confidence and use of WordTricks.

\section{CONCLUSIONS}

Based on the results the following recommendations are:

\section{Recommendations for PDA Devices}

The findings from the research conclude the following: In order for the firm to increase income and better serve clientele PDA devices are vital. More than 97\% of attorneys utilize their PDA device while out of the office. However $60 \%$ responded that they do not enter billable hours to clients for work performed via PDA device. This results in the loss of income for the firm. To be able for the law firm to accurately record billable hours via PDA devises a program such as TimeEntry software should be installed on all attorney PDA devices. As a result if attorneys do perform tasks for clients via PDA devices it would be automatically and electronically documented. Therefore the law firm would be able to track all billable hours from attorney PDA devices and ensure ROI from attorneys.

\section{Recommendations for FileSite}

FileSite is an extremely useful program that stores many document formats. It enables the user to access the documents/ files quickly and efficiently thereby saving time and costs. The study reveals that $80 \%$ of attorney's utilize FileSite on a daily basis. However in regards to the proper and effective storage of documents the research reveals that only $48 \%$ of emails are properly saved in FileSite followed by $64 \%$ for PDF files. When asked what prevents attorney's from properly utilizing FileSite more than $73 \%$ attributed it to training and complications followed by almost 19\% relying on their secretaries doing it for them. The improper storage of documents results in loss of time for the entire firm. This may be resolved by properly training all attorneys to learn FileSite so they can correctly store their documents. In the past the firm employed one secretary for a single attorney. However with increased competition and economic problems that ratio has dwindled to one secretary to every four attorneys. If the attorney's are compelled to learn FileSite they may be better able to use the client data and maximize their efficiency, which can result in the saving of time and costs.

\section{Recommendations for WordTricks}

The research manifests that WordTricks, although a useful technological tool that provides shortcuts and simplifies tasks for attorneys. Per the research only $11 \%$ of attorney's utilize WordTricks on a daily basis and over 38\% do not use it at all. Furthermore almost $45 \%$ of the sample responded to WordTricks as being barely helpful, not helpful or 


\section{Issues in Information Systems \\ Volume 14, Issue 1, pp.133-142, 2013}

they never use it. It should be noted that the firm allocates monetary resources to maintain and upgrade WordTricks in their computer systems. Therefore the law firm should share the data and loss of revenue to attorneys.

Furthermore the firm should eliminate attorneys from using WordTricks and permit the secretaries to utilize WordTricks. As a result WordTricks tools should be utilized only by secretaries to ensure that the firm's expenses and resources are properly allocated to maximize ROI by saving costs for WordTricks.

\section{Recommendations for Training}

The firm's management should implement a better training system for all employees. As mentioned above, $73 \%$ of attorneys point to a lack of training for the improper storage of documents in FileSite, which causes confusion for other employees, trying to access files and prolongs their work. Furthermore, the fact that $60 \%$ attorneys do not enter billable hours results in loss of income for the firm. One way to rectify the issue would be to implement a policy that requires all attorneys to attend a two-hour training class every month followed by two hours of one-onone training with an instructor the following month, while employed at the firm. This policy would be very similar to continuing legal education (CLE) credit hours all attorneys must complete to continue to practice law in the state of Florida. The proper and continuous training of all employees can save time, reduce costs and increase revenue for the firm.

\section{Recommendations for Gender, Age, Office Location and Experience}

Although the study revealed little statistical variance in the use of PDA's, and WordTricks based on gender, age, office location and experience, there was a larger inconsistency in comparison for the utilization of FileSite centered on age and experience. The data reveals that attorneys with 15 years of experience or less are more likely to properly store documents in FileSite. Furthermore the same group also utilizes FileSite at least three times per week. As a result the firm may want to emphasize training of FileSite for attorney's employed for more than fifteen years in an effort to save time and reduce costs.

\section{REFERENCES}

Babbie, E. (1990). Survey research methods ( $2^{\text {nd }}$ ed.). Belmont, CA: Wadsworth. Babbie, E. (2004). The practice of social research $\left(10^{\text {th }} \mathrm{ed}.\right)$. Belmont, CA Wadsworth/Thomson Learning. Creswell, J.W. (2003). Research design: Qualitative, quantitative and mixed methods approaches (2ND ed.). Thousand Oaks, CA: Sage Publications, Inc.

Fowler, F. J. (2002). Survey research methods ( $3^{\text {rd }}$ ed). Thousand Oaks, CA: Sage

Nesbary, D. K. (2000). Survey research and the World Wide Web. Boston: Allyn and Bacon.

Owusu, T. D. (2010). Barriers to technological acceptance in a legal environment: A case study of a Florida law firm. Robert Morris University). ProQuest Dissertations and Theses, , 205. Retrieved from http://search.proquest.com/docview/760103920?accountid=28365. (760103920). 